\title{
Effects of Emotional Labor and Compassion Competence on Dental Hygiene Performance in Dental Hygienists
}

\author{
Sun-Mi Kim and Young-Im $\mathrm{Kim}^{\dagger}$ \\ Department of Dental Hygiene, Vision College of Jeonju, Jeonju 55069, Korea
}

\begin{abstract}
Background: This study examines the relationship between the emotional labor and compassion competence of clinical dental hygienists. It attempted to provide basic data to establish a plan to increase the dental hygiene performance of clinical dental hygienists in the future by identifying the factors influencing the dental hygiene work performance.

Methods: This study is aimed at clinical dental hygienists working at the Jeollabuk-do Dental Clinic from April to June 2020 by the Convenience Sampling Method. An online survey site program was used to explain the purpose and purpose of the study on social media including the dental hygienist community, and distribute a URL that allows you to participate in the survey only if you agree to the study.

Results: In emotional labor, there was a significant difference in job satisfaction and marital status, and in compassion competence, there were significant differences in job satisfaction, final education, and marital status by group. In dental hygiene work performance, compassion competency showed a statistically significant positive correlation. In other words, it was found that the higher the compassion competence, the higher the dental hygiene work performance. It was found that the total number of years worked and the compassion competence that influenced dental hygiene work performance were statistically significant. Conclusion: In summary, in order to improve the dental hygiene work performance of clinical dental hygienists, it is necessary to compassion competence with the subject. To this end, it is believed that various supports, measures, and systematic management should be implemented to compassion competence of clinical dental hygienists.
\end{abstract}

Key Words: Compassion competence, Dental hygienists, Dental hygiene performance, Emotional labor

\section{Introduction}

Dental clinics are rapidly changing with the development of new medical technologies in the 4th industrial revolution era. The development of medical technology requires not only simple treatment, but also the expertise of human care with personality and professionalism for increased satisfaction of patients ${ }^{1)}$. Such high-quality services require strengthening of organizational competitiveness including increased competency of members ${ }^{2,3)}$ and human management. In particular, clinical dental hygienists need to perform basic duties of providing high-quality medical services, taking active stance on oral health problems according to various dental hygiene role requirements and rapidly changing medical environments, and having high intellectual level through professional education as competent professionals.

These social expectations and demands have led to emotional labor of clinical dental hygienists. Clinical dental hygienists are often asked to perform emotional labor to provide kind treatment to patients regardless of their emotions ${ }^{4)}$. They are also asked to hide and cover their emotions with that demanded by the organization for affective adaptation to the organization and achievement of organizational goals ${ }^{5}$, which lead to a high level of emotional labor in dental hygienists.

Additionally, compassion competency, which refers to action or skills triggered based on understanding and 
empathizing with the situation of patients, is an essential trait for clinical dental hygienists to reduce the mental, emotional, and physical difficulties and pain of patients ${ }^{6)}$.

Dental hygiene performance refers to the level to which dental hygienists reasonably perform their tasks and efficiently exercise their core competence based on their expertise. The dental hygienists carry out dental hygiene tasks to not only promote oral health through evidencebased dental hygiene knowledge, but also change the behavior of patients ${ }^{7)}$.

Thus, emotional labor and compassion competence based on the understanding of patients would be important factors for dental hygiene performance in clinical dental hygienists. The job satisfaction of dental hygienists through emotional labor and compassion competence also have significant effects on self and consumer satisfaction $^{8)}$, and therefore, assessment of dental hygiene performance may be a key aspect of studies.

However, there is a lack of studies on the effects of emotional labor and compassion competency on dental hygiene performance in dental hygienists. Therefore, the purpose of this study was to identify factors that affect the emotional labor and compassion competence of clinical dental hygienists and provide basic data to establish interventions to increase dental hygiene performance in the future.

\section{Materials and Methods}

\section{Study subjects}

From April to June, 2020, the convenience sampling method was used to recruit clinical dental hygienists working at dental clinics in Jeollabuk-do. The purpose and aim of the study were explained to dental hygienist communities and other social media using an online survey site program. The URL of the survey was provided only to those who agreed to participate in the study. G*POWER 3.1.9.7 program was used to calculate the sample size with the number of predictors of 3 , the median effect size of 0.15 , the significance level of 0.05 , and power of 0.95 in multiple regression analysis. A total of 149 subjects were required; however, 200 subjects were recruited considering possible drop-outs. Those 10 subjects who did not complete the survey or showed unsatisfactory responses were excluded, and data of 190 subjects (recovery rate 95\%) were included in the final analysis.

\section{Study item}

\section{1) Emotional labor}

A tool developed by Choi and $\mathrm{Kim}^{9)}$, based on the Korean emotional labor and workplace violence evaluation tool, modified according to the purpose of this study to assess emotional labor. The tool consisted of 16 items, which were evaluated on a 5-point Likert scale, and a higher score indicated greater emotional labor of the subject. Cronbach's alpha was 0.751 in this study.

\section{2) Compassion competence}

The compassion competence measurement tool, developed by Lee and Seomun ${ }^{6}$, was modified according to the purpose of this study to measure compassion competence. The tool consisted of 17 items, which were evaluated on a 5-point Likert scale, and a higher score indicated greater compassion competence of the subject. Cronbach's alpha was 0.826 in this study.

\section{3) Dental hygiene performance}

A tool developed by Ko et al. ${ }^{10)}$ was modified according to the circumstances of a clinical dental hygienist in order to measure dental hygiene performance. The tool consisted of 14 items, which were evaluated on a 5-point Likert scale, and a higher score indicated higher dental hygiene performance. Cronbach's alpha was 0.724 in this study.

\section{Data analysis}

ANOVA or t-test was conducted for analysis of emotional labor and compassion competence according to the general characteristics of the subjects, and Shceffe test was performed for post-hoc test. Pearson's correlation analysis was conducted to investigate the correlation between each variable. Additionally, hierarchical regression analysis was conducted to assess the effects of emotional labor and compassion competence on dental hygiene performance. Data were analyzed using SPSS ver. 18.0 (IBM Corp., Armonk, NY, USA) program, and a p-value 
less than 0.05 was considered significant.

\section{RESULTS}

\section{Emotional labor and compassion competence according to the general characteristics of clinical dental hygienists}

The differences in emotional labor and compassion competence according to the general characteristics of the subjects are shown in Table 1. In clinical dental hygienists, emotional labor was greater with higher job satisfaction ( $p<$ $0.001)$, education level $(\mathrm{p}<0.001)$, and married status $(\mathrm{p}<0.05)$ and the difference was significant. Similarly, compassion competence was greater with higher job satisfaction $(p<0.001)$, education level $(p<0.001)$, and married marital status $(\mathrm{p}<0.05)$ and the difference was significant.

\section{Correlation of emotional labor and compassion competence with dental hygiene performance in clinical dental hygienists}

The correlation of emotional labor and compassion competence with dental hygiene performance in clinical dental hygienists is shown in Table 2. Compassion competence showed a significant positive correlation with dental hygiene performance $(\mathrm{r}=0.687)$, suggesting that higher compassion competence led to greater dental hygiene performance.

\section{Factors affecting dental hygiene performance of clinical dental hygienists}

Hierarchical regression analysis was performed to assess factors of emotional labor and compassion competence that affect dental hygiene performance, and the results are shown in Table 3. Model 1 and 2 had F(p) of 3.291 ( $p<$ $0.001)$ and $13.061(p<0.001)$, respectively, confirming

Table 1. Differences between Emotional Labor and Compassion Competence according to the General Characteristics

\begin{tabular}{|c|c|c|c|c|c|c|}
\hline \multirow[b]{2}{*}{ Variable } & \multirow[b]{2}{*}{ Category } & \multirow[b]{2}{*}{ n (\%) } & \multicolumn{2}{|c|}{ Emotional labor } & \multicolumn{2}{|c|}{ Compassion competence } \\
\hline & & & $\begin{array}{l}\text { Mean } \pm \text { standard } \\
\text { deviation }\end{array}$ & $\begin{array}{l}\text { t or F(p) } \\
\text { Scheffe }\end{array}$ & $\begin{array}{l}\text { Mean } \pm \text { standard } \\
\text { deviation }\end{array}$ & $\begin{array}{l}t \text { or } F(p) \\
\text { Scheffe }\end{array}$ \\
\hline \multirow[t]{2}{*}{ Sex } & Male & $13(6.8)$ & $3.50 \pm 0.54$ & $0.60(0.570)$ & $3.62 \pm 0.51$ & $1.22(0.680)$ \\
\hline & Female & $177(93.2)$ & $3.58 \pm 0.50$ & & $3.79 \pm 0.49$ & \\
\hline \multirow[t]{5}{*}{ Age (y) } & $\leq 25$ & $60(31.6)$ & $3.68 \pm 0.47$ & $1.67(0.174)$ & $3.81 \pm 0.37$ & $0.29(0.881)$ \\
\hline & $26 \sim 30$ & $73(38.4)$ & $3.49 \pm 0.47$ & & $3.74 \pm 0.45$ & \\
\hline & $31 \sim 35$ & $25(13.2)$ & $3.63 \pm 0.57$ & & $3.80 \pm 0.74$ & \\
\hline & $36 \sim 40$ & $20(10.5)$ & $3.52 \pm 0.58$ & & $3.85 \pm 0.51$ & \\
\hline & $>40$ & $12(6.3)$ & $3.42 \pm 0.51$ & & $3.75 \pm 0.17$ & \\
\hline \multirow{5}{*}{ Career (y) } & $<1$ & $41(21.6)$ & $3.57 \pm 0.49$ & $0.69(0.593)$ & $3.77 \pm 0.36$ & $1.48(0.208)$ \\
\hline & $2 \sim 5$ & $64(33.7)$ & $3.62 \pm 0.46$ & & $3.74 \pm 0.43$ & \\
\hline & $6 \sim 10$ & $54(28.4)$ & $3.55 \pm 0.51$ & & $3.79 \pm 0.59$ & \\
\hline & $11 \sim 15$ & $17(8.9)$ & $3.43 \pm 0.57$ & & $3.73 \pm 0.50$ & \\
\hline & $>15$ & $14(7.4)$ & $3.69 \pm 0.71$ & & $4.08 \pm 0.63$ & \\
\hline \multirow[t]{5}{*}{ Job satisfaction } & Very satisfied & $15(7.9)$ & $3.85 \pm 0.30$ & $4.69 * * *$ & $4.08 \pm 0.50$ & $4.03 * * *$ \\
\hline & Satisfied & $70(36.8)$ & $3.70 \pm 0.49$ & & $3.87 \pm 0.52$ & \\
\hline & Common & $85(44.7)$ & $3.42 \pm 0.43$ & & $3.65 \pm 0.38$ & \\
\hline & Dissatisfied & $16(8.5)$ & $3.54 \pm 0.72$ & & $3.69 \pm 0.63$ & \\
\hline & Very dissatisfied & $4(2.1)$ & $3.33 \pm 1.08$ & & $3.54 \pm 0.86$ & \\
\hline \multirow[t]{3}{*}{ Education level } & College & $139(73.2)$ & $3.53 \pm 0.46$ & $1.98 * * *$ & $3.70 \pm 0.46$ & $6.82 * * *$ \\
\hline & University & $46(24.2)$ & $3.67 \pm 0.63$ & & $3.81 \pm 0.52$ & \\
\hline & Above university & $5(2.6)$ & $3.83 \pm 0.18$ & & $3.83 \pm 0.31$ & \\
\hline \multirow[t]{2}{*}{ Marital status } & Single & $141(74.2)$ & $3.55 \pm 0.61$ & $0.25 *$ & $3.75 \pm 0.61$ & $-1.33^{*}$ \\
\hline & Married & $49(25.8)$ & $3.58 \pm 0.47$ & & $3.88 \pm 0.43$ & \\
\hline
\end{tabular}

By t-test one-way ANOVA $(* \mathrm{p}<0.05, * * * \mathrm{p}<0.001)$. 
Table 2. Correlation between Moral Sensitivity and Psychological Well-Being and Job Engagement

\begin{tabular}{lccc}
\hline \multicolumn{1}{c}{ Classification } & Emotional labor & Compassion competence & Dental hygiene performance \\
\hline Emotional labor & 1 & & 1 \\
Compassion competence & 0.283 & $0.687^{* * *}$ & 1 \\
Dental hygiene performance & 0.309 & & 1 \\
\hline
\end{tabular}

$* * * \mathrm{p}<0.001$ by pearson's correlation analysis.

Table 3. Factors Affecting Research Subject's Dental Hygiene Performance

\begin{tabular}{|c|c|c|c|c|c|c|c|c|c|}
\hline \multirow[b]{2}{*}{ Variable } & \multirow[b]{2}{*}{ Category } & \multicolumn{4}{|c|}{ Model $1^{\mathrm{a}}$} & \multicolumn{4}{|c|}{ Model $2^{\mathrm{b}}$} \\
\hline & & B & $\begin{array}{l}\text { Standard } \\
\text { Error }\end{array}$ & $\beta$ & p-value & B & $\begin{array}{c}\text { Standard } \\
\text { error }\end{array}$ & $\beta$ & p-value \\
\hline Sex & (Ref. male) & -0.293 & 0.154 & -0.132 & 0.060 & 0.003 & 0.116 & 0.001 & 0.977 \\
\hline \multirow[t]{5}{*}{ Age (y) } & $($ Ref. $\leq 25)$ & & & & & & & & \\
\hline & $26 \sim 30$ & -0.071 & 0.111 & -0.061 & 0.524 & -0.151 & 0.087 & -0.131 & 0.087 \\
\hline & $31 \sim 35$ & -0.060 & 0.166 & -0.036 & 0.717 & -0.193 & 0.137 & -0.116 & 0.162 \\
\hline & $36 \sim 40$ & -0.089 & 0.163 & -0.049 & 0.586 & -0.522 & 0.182 & -0.286 & 0.005 \\
\hline & $>40$ & -0.124 & 0.194 & -0.054 & 0.524 & -0.640 & 0.226 & -0.277 & 0.005 \\
\hline \multirow[t]{5}{*}{ Work career $(\mathrm{y})$} & $($ Ref. $<1)$ & & & & & & & & \\
\hline & $2 \sim 5$ & 0.334 & 0.114 & 0.281 & 0.004 & 0.288 & 0.088 & 0.243 & 0.001 \\
\hline & $6 \sim 10$ & 0.402 & 0.149 & 0.323 & 0.008 & 0.300 & 0.114 & 0.241 & 0.009 \\
\hline & $11 \sim 15$ & 1.070 & 0.239 & 0.544 & $<0.001$ & 0.748 & 0.185 & 0.380 & $<0.001$ \\
\hline & $>15$ & 1.296 & 0.286 & 0.604 & $<0.001$ & 0.724 & 0.224 & 0.337 & 0.001 \\
\hline \multirow[t]{5}{*}{ Job satisfaction } & (Ref. very dissatisfied) & & & & & & & & \\
\hline & Dissatisfied & 0.180 & 0.284 & 0.089 & 0.528 & -0.204 & 0.221 & -0.101 & 0.358 \\
\hline & Common & 0.074 & 0.261 & 0.066 & 0.776 & -0.222 & 0.203 & -0.197 & 0.275 \\
\hline & Satisfied & 0.397 & 0.261 & 0.341 & 0.130 & -0.009 & 0.204 & -0.008 & 0.965 \\
\hline & $\begin{array}{l}\text { Very satisfied } \\
\text { (Ref. above university) }\end{array}$ & 0.561 & 0.286 & 0.270 & 0.051 & -0.026 & 0.225 & -0.012 & 0.909 \\
\hline Education level & College & -0.158 & 0.239 & -0.125 & 0.510 & -0.106 & 0.183 & -0.084 & 0.562 \\
\hline \multirow[t]{2}{*}{ Marital status } & $\begin{array}{l}\text { University } \\
\text { (Ref. single) }\end{array}$ & 0.086 & 0.248 & 0.066 & 0.730 & -0.111 & 0.190 & -0.085 & 0.559 \\
\hline & Married & 0.190 & 0.113 & 0.148 & 0.095 & 0.124 & 0.087 & 0.096 & 0.156 \\
\hline \multicolumn{2}{|l|}{ Emotional labor } & & & & & -0.031 & 0.062 & -0.028 & 0.617 \\
\hline \multicolumn{2}{|c|}{ Compassion competence } & & & & & 0.601 & 0.080 & 0.526 & $<0.001$ \\
\hline
\end{tabular}

${ }^{\mathrm{a}}$ Model 1: $\mathrm{F}(\mathrm{p})=3.291^{* * *}, \mathrm{R}^{2}=0.208$, adjusted $\mathrm{R}^{2}=0.145$. ${ }^{\mathrm{b}}$ Model 2: $\mathrm{F}(\mathrm{p})=13.061^{* * *}, \mathrm{R}^{2}=0.563$, adjusted $\mathrm{R}^{2}=0.519$.

that the models were suitable. In Model 1, variables of general characteristics were converted into dummy variables for analysis, and in Model 2, emotional labor and compassion competence variables were added to Model 1.

To confirm that the assumptions of regression analysis were satisfied, tolerance and variance inflation factor (VIF) of each variable were assessed. Tolerance was $0.075 \sim 0.886$, and VIF was less than 10 , suggesting no multicollinearity between the independent variables.

In Model 1 and 2, the total number of years worked and compassion competence, respectively, affected dental hygiene performance. The explanatory power of Model 2 was $51 \%$, which was $37 \%$ greater than the $14 \%$ of Model 1 , and the model was statistically significant.

\section{Discussion}

The recent development of medical technology has introduced new knowledge and information that need to be acquired by medical staff, followed by subsequent expansion of and increased competition between medical institutions, increased consumer demand, and subdivision 
and specialization of work $^{11)}$. These changes demand emotional labor and compassion competence in clinical dental hygienists to understand the patients with a sense of responsibility. In this study, the relationship between emotional labor and compassion competence of clinical dental hygienists was assessed in order to provide basic data for future interventions on increasing dental hygiene performance.

The differences in emotional labor according to general characteristics were analyzed, and higher job satisfaction and education level and married marital status led to a significant increase in emotional labor. $\mathrm{Kim}^{12)}$ previously demonstrated that lack of clinical experience, lower or higher salary led to increased emotional labor and Lee et al. ${ }^{13)}$ reported that those who work at dental clinics and have intentions to work at different clinics had higher emotional labor. How does the subject affect emotional labor of dental hygienists is also increased as the size of the hospital increases ${ }^{4,14}$, and increased amount of work and unfair treatment perceived by dental hygienists lead to greater emotional labor ${ }^{15)}$. These results reflect that clinical dental hygienists manage facial expressions and speed in a professional manner to give trust to the patients during the emotional labor and that they make effort to offer sincere hospitality to maintain continuous rapport with the patients ${ }^{10)}$.

In the current study, compassion competence was significantly greater with higher job satisfaction and education level and married marital status. In a study of nurses by Lee and Lee ${ }^{16)}$, compassion competence was significantly different according to educational level, and in a study by Lee ${ }^{17}$, compassion competence was greater with higher age, increased clinical experience, higher position at work, and higher education level. Clinical nurses with high compassion competence often try to respond immediately when changes are observed in patients. These nurses closely observe the subjects, listen to the patients, and show verbal and non-verbal responses to patients ${ }^{18)}$. Although there is no previous outcome variables of compassion competence in clinical dental hygienists for comparison of findings, clinical dental hygienists require increased knowledge, skills, attitudes, and experiences to perform their given tasks, including compassion competence to listen and communicate with patients, compared to other medical staffs. It would be necessary to highlight the importance of compassion competence and study the effects of compassion competency outcome variables on dental hygiene performance in clinical dental hygienists.

Model 2, which included 2 more variables in addition to the general characteristics of subjects of Model 1, had $37 \%$ greater explanatory power than Model 1, suggesting that compassion competence was a factor that affected the dental hygiene performance of clinical dental hygienists. In a study by Lee and $\mathrm{Kim}^{19}$ ), compassion affected dental hygiene performance in dental hygienists, and similarly, compassion also had effects on work performance in nurses. Additionally, Lee ${ }^{17)}$ reported that nurses with empathic concern and higher compassion showed greater work performance. The current study demonstrated that compassion competency was the factor with the greatest effects on dental hygiene performance in clinical dental hygienists. Therefore, the development of differentiated programs and education would be necessary to increase compassion competency in dental hygienists and improve their performance.

The limitations of this study are as follows. There were no previous studies that specifically assessed factors related to dental hygiene performance of clinical dental hygienists, and thus. objective comparison and explanation of the findings were limited. This was also a crosssectional study of dental hygienists in certain regions. In future studies, various structural models with different variables and diversified sampling of the subjects would be necessary.

\section{Notes}

\section{Conflict of interest}

No potential conflict of interest relevant to this article was reported.

\section{Ethical approval}

This study was approved by the Wonkwang University Bioethics Review Committee (IRB No. WKIRB-202009SB-055). 


\section{Author contributions}

Conceptualization: Young-Im Kim. Data acquisition: Young-Im Kim and Sun-Mi Kim. Formal analysis: Sun-Mi Kim. Funding: Young-Im Kim. Supervision: Young-Im Kim. Writing - original draft: Young-Im Kim and Sun-Mi Kim. Writing_review \& editing: Young-Im Kim.

\section{ORCID}

Sun-Mi Kim, https://orcid.org/0000-0003-0718-9419

Young-Im Kim, https://orcid.org/0000-0002-3926-5909

\section{Acknowledgements}

This research was supported by funds of Vision College of Jeonju.

\section{References}

1. Kim MJ, Lim CY, Son JL: Effect of emotional labor on somatization among dental hygienists in an area. J Dent Hyg Sci 19: 113-121, 2019. https://doi.org/10.17135/jdhs.2019.19.2.113

2. Lee SK, Lee DJ, Jang EY, Choi DK, Son KH: A study on the relationships between self-leadership and organizational citizenship behavior according to styles of leadership. J Digit Converg 8: 123-136, 2010.

3. Kim JH, Han SJ: The effect of self-leadership on organizational effectiveness and job performance in dental hygienist. J Korean Soc Dent Hyg 16: 1079-1092, 2016. https://doi.org/10.13065/jksdh.2016.16.06.1079

4. Jung EK: Relationship between emotional labor and burnout among dental hygienists. J Korean Soc Dent Hyg 16: 53-59, 2016. https://doi.org/10.13065/jksdh.2016.16.01.53

5. Grandey AA: Emotion regulation in the workplace: a new way to conceptualize emotional labor. J Occup Health Psychol 5: 95-110, 2000. https://doi.org/10.1037//1076-8998.5.1.95

6. Lee YJ, Seomun G: Development and validation of an instrument to measure nurses' compassion competence. Appl Nurs Res 30: 76-82, 2016. https://doi.org/10.1016/j.apnr.2015.09.007

7. Kwon JY, Lee SY: Relationship of between task performance, job satisfaction, and organizational contribution of dental hygienists. J Dent Hyg Sci 16: 302-309, 2016.

https://doi.org/10.17135/jdhs.2016.16.4.302

8. Slavitt DB, Stamps PL, Piedmont EB, Haase AM: Nurses' satisfaction with their work situation. Nurs Res 27: 114-120, 1978.

9. Choi HJ, Kim MY: Psychometric properties of Korean version of Nurse Emotional Labor Strategy Scale (K-NELSS). J Korean Acad Nurs Adm 24: 161-170, 2018. https://doi.org/10.11111/jkana.2018.24.2.161

10. Ko YK, Lee TW, Lim JY: Development of a performance measurement scale for hospital nurses. J Korean Acad Nurs 37: 286-294, 2007. https://doi.org/10.4040/jkan.2007.37.3.286

11. Won YS, Oh HN: The effects of job stress and psychosocial stress among dental hygienists. J Dent Hyg Sci 15: 679-687, 2015. https://doi.org/10.17135/jdhs.2015.15.5.679

12. Kim YI: A study on effects of emotional labor and emotional intelligence of dental hygienist on organizational effectiveness. J Korea Acad-Ind Cooper Soc 20: 390-396, 2019. https://doi.org/10.5762/KAIS.2019.20.9.390

13. Lee MJ, Kim YN, Lee SY: A study on factors affecting emotional labor of clinical dental hygienists. J Dent Hyg Sci 15: 113-118, 2015. https://doi.org/10.17135/jdhs.2015.15.2.113

14. Choi HJ, Bang HJ, Chung EY, Seo YJ: Factors that affect the level of emotional labor in dental hygienists. J Dent Hyg Sci 14: 295-301, 2014. https://doi.org/10.17135/jdhs.2014.14.3.295

15. Hyeong JH, Jang YJ: A study on emotional labor and occupational stress in dental hygienists. J Korean Soc Dent Hyg 19: 1003-1013, 2019. https://doi.org/10.13065/jksdh.20190086

16. Lee JY, Lee MH: Influencing factors of empathic competence and occupational stress of nurses on their ego-resilience. J Korean Acad Soc Home Health Care Nurs 26: 19-26, 2019. https://doi.org/10.22705/jkashcn.2019.26.1.19

17. Lee HK: Converged influencing factors on compassion competence in clinical nurses. J Korea Converg Soc 6: 15-22, 2015. https://doi.org/10.15207/JKCS.2015.6.5.015

18. Jo KH, Park AR, Lee JJ, Choi SJ: The effect of suffering 
experience, empathy ability, caring behaviors on terminal care performance of clinical nurses. Korean J Hosp Palliat Care 18: 276-284, 2015.

https://doi.org/10.14475/kjhpc.2015.18.4.276

19. Lee BH, Kim JS: The relationship between coaching behaviors of dental managers, job satisfaction and job performance of dental hygienists. Korean J Health Serv Manag 6: 121-130, 2012.

https://doi.org/10.12811/kshsm.2012.6.4.121 